\title{
Obesity Paradox in Kidney Diseases
}

\author{
Cagla Pinarli* \\ Department of Nutrition and Dietetics, Istanbul Gedik University, Turkey
}

*Corresponding author: Cagla Pinarli, Faculty of Health Sciences Nutrition and Dietetics Departments, Istanbul Gedik University, Istanbul, Turkey.
Received Date: March 01, 2021

Published Date: March 09, 2021

\begin{abstract}
Obesity is one of the most important health problem in the world. Elevated mortality risk can be seen with obesity, diabetes, hypertension, glomerular hyperfiltration, chronic kidney disease, and cardiovascular diseases. However, it has been observed that obesity positively affects survival especially in people with chronic kidney disease, elderly people, chronic heart failure, chronic obstructive pulmonary disease, cancer, acquired immune deficiency syndrome and rheumatoid arthritis. This situation has been called the obesity paradox. Studies are showing that the obesity paradox is valid in dialysis patients. Examinations have shown that the obesity paradox is affected by many factors such as ethnic origin, fat-muscle mass, and body mass index (BMI). The hypothetical pathophysiology of the obesity paradox reveals how obesity improves survival in chronic kidney disease.
\end{abstract}

Keywords: Obesity paradox; Obesity; Kidney diseases

Abbreviations: BMI: Body Mass Index, CKD: Chronic Kidney Disease, ESRD: End-Stage Renal Disease

\section{Introduction}

People with chronic kidney disease (CKD) have an increased mortality rate with end-stage renal disease (ESRD) and dialysis treatment. Mortality reaches up higher in the first months of dialysis therapy [1]. The mortality level seen in patients with chronic kidney disease is even higher than the risk of death seen in many types of cancer [2]. According to the results of randomized clinical studies, no significant benefit was found between improvement in CKD-related specific factors (anemia, iron deficiency, hyperphosphatemia, hyperparathyroidism, vitamin D deficiency, hypercalcemia, and dialysis dose) and survival [3,4]. At this point, it has been observed that the obesity paradox has a significant relationship with survival $[5,6]$.

\section{Obesity and CKD}

Studies show that obesity, in general, has an accelerating effect on the risk of CKD [7]. According to the results of a study, it is thought that weight loss may have an anti-CKD effect. As a consequence of some bariatric surgery operations, a reduction in EGFR has been observed. It has been stated that this situation can prevent glomerular hyperfiltration and decrease the risk of CKD [8]. On the other hand, if CKD occurs, increased BMI is paradoxically related to survival [9].

\section{Hypothetical Pathophysiology of the Obesity Paradox}

The pathophysiology of protein-energy deficiency in CKD occurs with inflammation. Thus, inflammatory cytokines (interleukin-6, tumor necrosis factor- $\alpha$ ) repress appetite, cause hypoalbuminemia and muscle destruction. By the loss of muscle and fat mass, inflammation, increased cardiovascular disease, and death result. Obesity has a potential protective effect against protein-energy deficiency. Obesity defends against inflammation and reduces the risk of cardiovascular disease and death. For example, patients with excess adipose tissue are at a lower riskfor protein-energy deficiency 
because they have more energy and protein reserves. Therefore, a lower risk of death is observed in dialysis patients with high BMI or creatine concentration $[10,11]$. On the other hand, obesity is related to short-term hemodynamic stability. Fluid accumulation and heart failure are seen in many CKD patients on dialysis. In contrast to similar pulmonary capillary occlusion pressure, increased systolic blood pressure is seen in obese and overweight subjects. This provides better tolerance to the ultrafiltration rate and high volume occurring during dialysis [12]. The change in cytokines provides better results in obese individuals. Adipose tissue produces tumor necrosis factor- $\alpha$ receptor. Increased number of receptors play a cardioprotective role. Body fat and weight loss boost the release of lipophilic hexachlorobenzene and other chlorinated hydrocarbons. This demonstrates the enhanced risk of mortality in ESRD patients. Obese cases have an increased lipid and lipoprotein combination. This can calm the circulating endotoxins. Eventually, cardiovascular diseases and death occur [13,14]. Importantly, it should be emphasized that enhanced BMI level due to increased muscle mass was found to be more effective in the obesity paradox (compared to fat mass) [15].

\section{Ethnicity and Obesity Paradox}

There are also studies showing how ethnicity affects the obesity paradox. The obesity paradox was found to be stronger in African Americans in a study conducted on dialysis patients [16]. In another study, the stronger relationship was observed between elevated BMI and survival in African Americans, Asian Americans, Caucasians and Hispanics [17].

\section{Conclusion}

Obesity paradox is common in chronic diseases, especially in conditions such as advanced CKD, where weight loss is common. Studies show that obesity, in general, has an increasing effect on the risk of CKD disease, but on the other hand, if CKD occurs, the increased BMI is paradoxically associated with survival. It has been observed that weight loss leads to an increased risk of death in dialysis patients. Weight loss, primarily in the earliest months, is linked to increased mortality. An improvement in fat and muscle mass is generally associated with improved survival in people with CKD. The increase in muscle mass has an extra protective effect. Studies on the relationship between ethnicity and the obesity paradox show that the obesity paradox is observed in some ethnicity more powerfully.

\section{Acknowledgement}

None.

\section{Conflict of Interest}

Author declares no conflicts of interest.

\section{References}

1. Saran R, Li Y, Robinson B, Abbott KC, Agodoa LYC, et al. (2016) US Renal Data System 2015 Annual Data Report: Epidemiology of Kidney Disease in the United States. Am J Kidney Dis 67(3): S1-S305.

2. Li L, Kalantar-Zadeh K (2013) Obesity that makes kidney cancer more likely but helps fight it more strongly. J Natl Cancer Inst 105(24): 18481849.

3. Paniagua R, Amato D, Vonesh E, Correa-Rotter R, Ramos A, et al. (2002) Effects of increased peritoneal clearances on mortality rates in peritoneal dialysis: ADEMEX, a prospective, randomized, controlled trial. J Am Soc Nephrol 13(5): 1307-1320.

4. Eknoyan G, Beck GJ, Cheung AK, Daugirdas JT, Greene T, et al. (2002) Effect of dialysis dose and membrane flux in maintenance hemodialysis. $\mathrm{N}$ Engl J Med 347(25): 2010-2019.

5. Park J, Ahmadi SF, Streja E, Molnar MZ, Flegal KM, et al. (2014) Obesity paradox in end-stage kidney disease patients. Prog Cardiovasc Dis 56(4): 415-425.

6. Kalantar-Zadeh K, Rhee CM, Amin AN (2014) To legitimize the contentious obesity paradox. Mayo Clin Proc 89(8): 1033-1035.

7. Kalantar-Zadeh K, Rhee CM, Chou J, Ahmadi SF, Park J, et al. (2017) The Obesity Paradox in Kidney Disease: How to Reconcile it with Obesity Management. Kidney Int Rep 2(2): 271-281.

8. Friedman AN, Wolfe B (2016) Is Bariatric Surgery an Effective Treatment for Type II Diabetic Kidney Disease. Clin J Am Soc Nephrol 11(3): 528-535.

9. Ahmadi SF, Zahmatkesh G, Ahmadi E, Streja E, Rhee CM, et al. (2015) Association of Body Mass Index with Clinical Outcomes in Non-Dialysis-Dependent Chronic Kidney Disease: A Systematic Review and Meta-Analysis. Cardiorenal Med 6(1): 37-49.

10. Yao Q, Lindholm B, Stenvinkel P (2004) Inflammation as a cause of malnutrition, atherosclerotic cardiovascular disease, and poor outcome in hemodialysis patients. Hemodial Int 8(2): 118-129.

11. Qureshi AR, Alvestrand A, Divino-Filho JC, Gutierrez A, Heimbürger O, et al. (2002) Inflammation, malnutrition, and cardiac disease as predictors of mortality in hemodialysis patients. J Am Soc Nephrol 2002 13(1): S28-S36.

12. Park J, Rhee CM, Sim JJ, Kim YL, Ricks J, et al. (2013) A comparative effectiveness research study of the change in blood pressure during hemodialysis treatment and survival. Kidney Int 84(4): 795-802.

13. Jandacek RJ, Anderson N, Liu M, Zheng S, Yang Q et al. (2005) Effects of yo-yo diet, caloric restriction, and olestra on tissue distribution of hexachlorobenzene. Am J Physiol Gastrointest Liver Physiol 288(2): G292-G299.

14. Rauchhaus M, Coats AJ, Anker SD (2000) The endotoxin-lipoprotein hypothesis. Lancet 356(9233): 930-933.

15. Beddhu S, Pappas LM, Ramkumar N, Samore M (2003) Effects of body size and body composition on survival in hemodialysis patients. J Am Soc Nephrol 14(9): 2366-2372.

16. Glanton CW, Hypolite IO, Hshieh PB, Agodoa LY, Yuan CM, et al. (2003) Factors associated with improved short term survival in obese end stage renal disease patients. Ann Epidemiol 13(2):136-143.

17. Johansen KL, Kutner NG, Young B, Chertow GM (2006) Association of body size with health status in patients beginning dialysis. Am J Clin Nutr 83(3): 543-549. 